\section{FRANCISCO MENÉNDEZ FRENTE A ALEJO CARPENTIER, O SOBRE LA VIGENCIA DE LOS MITOS DE LA CONQUISTA}

\author{
TEODOSIO FERNÁNDEZ
}

Universidad Autónoma de Madrid

Teodosio.fernandez@uam.es
Teodosio Fernández

Catedrático de literatura hispanoamericana de la Universidad Autónoma de Madrid. Su actividad docente e investigadora se ha centrado fundamentalmente en la literatura hispanoamericana de los siglos XIX y XX y la significación de los procesos políticos y culturales en ésta. Entre sus publicaciones se cuentan: El teatro chileno contemporáneo (1941-1973) (1982), La poesía hispanoamericana en el siglo XX (1987), La poesía hispanoamericana hasta el final de modernismo (1989), Los géneros ensayísticos hispanoamericanos (1990) y Literatura hispanoamericana: sociedad y cultura (1998), entre otras. Ha editado Amalia de José Mármol (1984), Huasipungo de Jorge Icaza (1994) y Garduña de Manuel Zeno Gandía (1996), así como el volumen Teoría y crítica literaria de la emancipación hispanoamericana (1997).

\title{
RESUMEN
}

Con objeto de valorar la opinión de Alejo Carpentier sobre los mitos de la conquista, tan relevantes para interpretar la historia de América como una crónica de lo real maravilloso, se analizan los testimonios del siglo XVIII relacionados con la leyenda de la ciudad de los Césares, con especial atención para los diarios en los que Francisco Menéndez dejó constancia de sus viajes a la laguna Nahuel Huapi, los últimos impulsados por esa persistente fantasía patagónica.

Palabras clave: Historia, mito, racionalismo ilustrado, realidad maravillosa, Alejo Carpentier, Francisco Menéndez, Patagonia, Ciudad de los Césares.

\section{ABSTRACT}

In order to assess the opinion of Alejo Carpentier about the myths of conquest, as relevants to interpret American history as a chronicle of the real maravilloso, we analyze the Eighteenth Century testimonies related to the legend of the city of the Caesars, with special attention to the newspapers in which Francisco Menéndez recorded his tours to the lake Nahuel Huapi, the last inspirated by the persistent patagonic fantasy.

Keywords: History, Myth, Enlightenment rationalism, really wonderful, Alejo Carpentier, Francisco Menendez, Patagonia, City of the Caesars.

En el prólogo a El reino de este mundo, Alejo Carpentier encontraba significativo «que, en 1780 , unos cuerdos españoles, salidos de Angostura, se lanzaran todavía a la busca de El Dorado, y que, en los días de la Revolución Francesa - ¡vivan la Razón y el Ser Supremo!-, el compostelano Francisco Menéndez anduviera por tierras de Patagonia buscando la Ciudad Encantada de los Césares» (1949a, pp. 13-14). Lo había creído así al menos desde que en 1947, en Venezuela, sobrevolara el curso alto del río Caroní y las formaciones geológicas de la Gran Sabana hasta aterrizar en Santa Elena de Uairén, desde donde, también en avión, viajó a Ciudad Bolívar y a Puerto Ayacucho para remontar en barco el río Orinoco. Resultado de aquellas experiencias fueron cinco artículos publicados de inmediato en El Nacional de Caracas y luego en La Habana por Carteles, ya en 1948. Los paisajes del Alto Caroní le llevaron entonces a recordar con insistencia que a finales del siglo XVIII seguía activa la leyenda de El Dorado, «ese fabuloso reino de Manoa, de imprecisa ubicación, que los hombres buscaron incansablemente, casi hasta los
Francisco Menéndez frente a Alejo Carpentier, o sobre la vigencia de los mitos de la conquista 


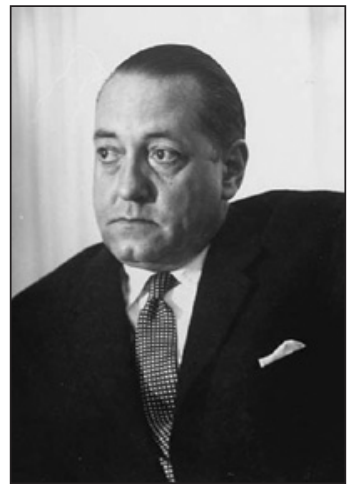

Fotografía de Alejo Carpentier

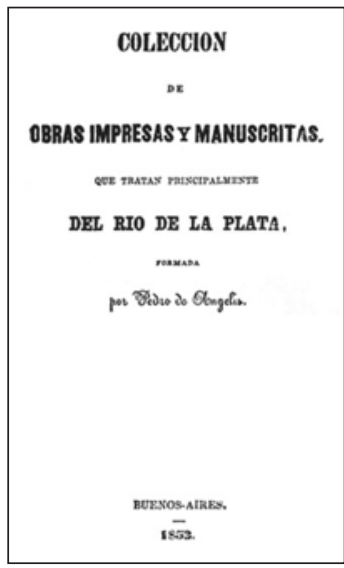

1

Esos establecimientos en el río Negro estaban tras las informaciones de algún indígena sobre españoles establecidos "donde entra en el mar el río Meuquen - Neuquen, a la otra parte de la cordillera», según constaba en la «Declaración del capitán D. Fermín Villagrán, sobre la ciudad de los Césares (1871)» (Angelis, 1836b, p. 42; cursivas en el original).

Francisco Menéndez frente a Alejo Carpentier, o sobre la vigencia de los mitos de la conquista

TEODOSIO FERNÁNDEZ días de la Revolución francesa» (1985a, p. 170), admirándose de que en los días racionalistas de la Ilustración se hubiera encendido de nuevo ese espejismo «adormecido desde los últimos días del siglo XVI» (1985b, p. 180). En efecto, las últimas expediciones en busca de El Dorado fueron las enviadas desde Angostura -Santo Tomás de la Nueva Guayana de la Angostura del Orinoco, hoy Ciudad Bolívar- por Manuel Centurión, gobernador de la Guayana, a la laguna Parime, en 1773 y 1775. Para que Carpentier pudiera confirmar la pervivencia y vigencia de los mitos en América, lejos de allí y cuando en 1794 París elevaba cantatas «a la Razón y al Ser Supremo» (1985b, p. 181) -en mayo de aquel año el culto de la Razón, instaurado meses antes, fue sustituido en Francia por el culto del Ser Supremo como religión del estado-, el compostelano Francisco Menéndez andaba por tierras de la Patagonia en busca de la Ciudad Encantada de los Césares. Efectivamente, el franciscano Francisco Menéndez -en realidad un asturiano de Villaviciosa educado en Santiago de Compostela- realizó su última expedición en busca de esa misteriosa ciudad, cuya leyenda había impulsado en buena medida las exploraciones del extremo sur del continente desde que hacia 1528 la expedición comandada por Francisco César saliera del fuerte Santi Spiritus, construido cerca del río Paraná, para regresar con noticias de haber visto extraordinarias riquezas en lugares que después nadie consiguió identificar con precisión.

La leyenda de la ciudad de los Césares constituye el mejor pretexto para volver sobre la revisión de los mitos de la conquista que Carpentier proponía, por ser la más persistente y también por el interés de los testimonios que confirman su vigencia, en buena parte reunidos por Pedro de Ángelis en Derroteros $y$ viajes a la Ciudad Encantada, o de los Césares, que se creía existiese en la cordillera, al sud de Valdivia e incluidos en su Colección de obras y documentos relativos a la historia antigua y moderna de las provincias del Rio de la Plata. Como el propio De Ángelis hizo constar, esa información provenía de los testimonios aducidos en 1782 por el Dr. Pérez de Uriondo, Fiscal de Chile, quien «no solo creía en los Césares, sino que se esforzaba a que todos les creyesen» (1836a, p. IV), lo que no había sido obstáculo para que examinara el origen de las noticias y descartara las que pudo explicar, como las derivadas del esta- blecimiento de poblaciones españolas que el gobierno del Virreinato del Río de la Plata intentaba desde diciembre de 1778 en la $\mathrm{Ba}$ hía sin Fondo, en la desembocadura del Río Negro ${ }^{1}$. Como base de los argumentos con que Pérez de Uriondo pretendía favorecer la expedición que trataba de organizar el capitán Manuel Josef de Orejuela, nada mejor que el documento más antiguo de los publicados por De Ángelis: el titulado «Derrotero de un viaje desde Buenos Aires a los Césares, por el Tandil y el Volcán, rumbo al sud-oeste», informe al parecer enviado en 1707 a la corte de Madrid por Silvestre Antonio de Rojas, quien aseguraba haber vivido mucho años entre los indios pehuenches, que comerciaban con «los Césares españoles», a los que un río separaba de «los indios Césares», que eran «los verdaderos Césares» (Ángelis, 1836c, pp. 5 y 4), según él mismo habría podido comprobar. Y la muestra más destacada de la pervivencia de esa ciudad utópica en la imaginación dieciochesca es la «Relación de las noticias adquiridas sobre una ciudad grande de españoles, al sud de Valdivia, e incógnita hasta el presente, por el capitán D. Ignacio Pinuer (1774)» (Ángelis, 1836d), ciudad que los españoles habrían fundado no lejos del Río Bueno y del lago Ranco tras abandonar el fuerte de Osorno asediado por los indígenas, que lo destruyeron en 1602, como ocurrió con otras ciudades de la Araucanía tras la derrota que los españoles sufrieran a finales de 1598 en la batalla de Curalaba. Tal informe iba dirigido a Agustín de Jáuregui y Aldecoa, entonces gobernador de Chile, quien informó puntualmente del caso a Manuel de Amat y Junient, a la sazón virrey del Perú, y fue sin duda motivo fundamental para que en los años siguientes se hicieran expediciones desde Chiloé hacia los territorios casi inaccesibles de la cordillera de los Andes y de sus estribaciones.

«Hay épocas en que la razón se ofusca al contemplar objetos nuevos e inusitados; y expuesto el hombre más juicioso a una serie continua de impresiones violentas, deja de analizarlas, y baja insensiblemente al nivel de las inteligencias vulgares, que todo lo ponderan y admiran», reflexionaba Pedro de Ángelis (1836a, p. V) a propósito de los documentos que había seleccionado y que con el tiempo podrían justificar la opinión y el entusiasmo de Carpentier ante ese y otros mitos de la conquista. Tal vez, sin embargo, 
no falten razones para cuestionar las actitudes de uno y del otro ante la mentalidad que creyeron propia de ese siglo XVIII hispanoamericano. La estancia de Silvestre Antonio de Rojas en la ciudad de los Césares debió de concluir pocos años antes de 1673, fecha ya lejana de la muerte que el jesuita Nicolás Mascardi encontró a manos de los indígenas, al parecer poyas o puelches, cuando desde el lago Nahuel Huapi trataba de adentrarse en las tierras patagónicas del este, lo que de algún modo habría de justificar la atención que luego dedicaron al tema miembros de la Compañía de Jesús como José Cardiel, Pedro Lozano o Tomás Falkner, al menos según se desprende de sus cartas publicadas. Cardiel, que había conocido o tenía noticia del informe de Rojas -él era ese "cristiano español o mixto" autor de «una relación, que anda por Buenos Aires, en que dice en suma que llevándole cautivo, o de otra forma, llegó a una de estas ciudades, de que cuenta grandezas, y que en cierto paraje antes de llegar había un cerro de diamantes, y otro en otro paraje de oro» (Ángelis, 1836e, p. 15)-, parecía especialmente interesado en la evangelización de las casi completamente desconocidas tierras de los patagones, y también en aclarar el destino de los muchos españoles perdidos desde el siglo XVI en el estrecho de Magallanes, a los que también cabía relacionar con la ciudad de los Césares, convencido, como estaba, de que las noticias sobre esa ciudad «están mezcladas con muchas fábulas, mas habiéndose perdido tantos navíos no puede menos de haber algo de lo que se dice, pues que no hay mentira que no sea bija de algo» (Ángelis, 1836e, p. 16; cursiva en el original), según escribía en 1746 en la estancia jesuítica de San Antonio de Areco, cerca de Buenos Aires. Los resultados negativos de sus propias búsquedas no le impedían mantener su fe en la existencia de ignoradas poblaciones españolas, «quizá con algunas minas de oro y plata» (Ángelis, 1836e, p. 13). Parece haber compartido esa fe Pedro Lozano, aunque al hacer una relación pormenorizada de la pérdida de las ciudades chilenas de Santa Cruz de Loyola, Chillán, Infantes de Angol, la Imperial, Valdivia, Villa Rica y desde luego Osorno -despoblada tras romper el asedio con la ayuda de trescientos hombres que al mando del coronel Francisco del Campo envió don Luis de Velasco, virrey del Perú- en su Historia de la Compañia de Jesús, en la provincia del Paraguay, publica- da en Madrid en 1754 y 1755, ya no hiciera alusión a ciudad posterior alguna (1754, p. 348). Al morir en 1752 había dejado inédita una Historia del Paraguay, Río de la Plata y Tucumán-en 1873 la dio a la imprenta Andrés Lamas, dentro de la «Colección de Obras, Documentos y Noticias inéditas o poco conocidas para servir a la historia física, política y literaria del Río de la Plata»- donde no faltaban referencias a la laguna del Dorado y sobre todo al imperio de Paytiti regido por el gran Moxo, detalladamente descrito por Martín del Barco Centenera en su poema histórico $L a$ Argentina o La conquista del Río de la Plata, pero era para concluir que todas las grandezas registradas eran «tan poco verosímiles, que es menester ser poco críticos para no llamarlas patrañas o ficciones poéticas» (1873, I, p. 111), aduciendo en favor de su razonamiento diversas expediciones inútiles que habían intentado encontrar aquel imperio incluso en tiempos relativamente recientes.

No es imposible entrever las razones de esas vacilaciones o cambios de opinión. En «Fábula de las Batuecas, y países imaginarios», Benito Jerónimo Feijoo se había burlado del supuesto aislamiento de esa tierra española, incógnita según la leyenda hasta tiempos de Felipe II, para después hacer cuenta «de algunos países, o poblaciones, cuya existencia se ha creído un tiempo, o aún ahora se cree, los cuales no tienen, ni han tenido más ser que el que tienen los entes de razón» (1730, p. 250): la isla Atlántida, la isla Panchaya, la provincia de Ansen, el reino de Catai, el $\mathrm{Pa}$ raíso Terrenal, la isla de San Borondón, la isla de Frislandia y la de Java menor, para pasar después a ocuparse con la misma intención del Gran Paititi, El Dorado, la Gran Quivira, la Ciudad de los Césares y hasta las lejanas islas de Palaos, allá por las Filipinas, fantasías todas estas últimas relacionadas con la alocada y perversa búsqueda de riquezas que parecía ahora un factor decisivo - «el oro de las Indias nos tiene pobres» $(1730$, p. 267$)-$ de la decadencia de España. Pedro Lozano conocía bien ese «discurso", incluso para corregir alguna de las noticias que daba $\mathrm{Feijoo}^{2}$, y mostraba que también él, a pesar de su inclinación a creer en los milagros, al abordar asuntos profanos prefería prestar atención a las pruebas -no era culpa suya que se revelasen falsas con el tiempo-y olvidarse de rumores o habladurías. No es extraño, pues, que Lozano, tras acumular testimonios en favor de la existencia de la

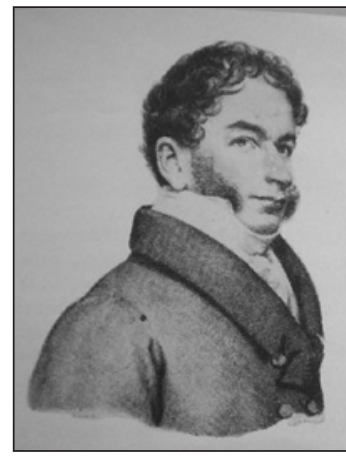

Grabado de Pedro de Ángelis

Feijoo había mencionado al gallego Benito Quiroga, que en tiempos de Carlos II se habría arruinado financiando expediciones en busca del Gran Paititi, y Lozano precisaba que «no a los últimos años del reinado del señor Carlos II como escribe el reverendísimo padre misionero fray Benito Feijoo en su eruditísimo Teatro, sino a los principios de su gobierno, o a los últimos del de la Reina Madre según refiere el padre Cortés Osorio en los Reparos Historiales, impresos en 1677», fue cuando sucedió «a don Benito de Rivera y Quiroga que entrando por la Laricaja a esta importante conquista con suficiente número de soldados costeados a sus expensas, no hallaron Paititi, ni tales cerros, ni más corte que unas tristes rancherías de indios chontales, entre quienes vivía muy contenta la suma pobreza, como en un país inculto y estéril, y faltos de todo si no es de miseria» (1873, p. 113). En efecto, mientras denunciaba los muchos errores advertidos en los Tratados históricos, políticos, éticos y religiosos de la monarquía de China que el dominico Domingo Fernández de Navarrete había publicado en 1676, el jesuita Juan Cortés Osorio se había referido a la expedición realizada por «don Benito de Ribera, en nombre de su tío Antonio López de Quiroga», cuando era virrey del Perú el Conde de Lemus -lo fue desde principios de 1669 hasta su muerte, acaecida el 6 de diciembre de 1672-, que, como tantas otras que también recordó, no habían encontrado otra cosa que «el precioso fruto del desengaño» (1677, fol. 97 rvv.)

Francisco Menéndez frente a Alejo Carpentier, o sobre la vigencia de los mitos de la conquista

TEODOSIO FERNÁNDEZ 


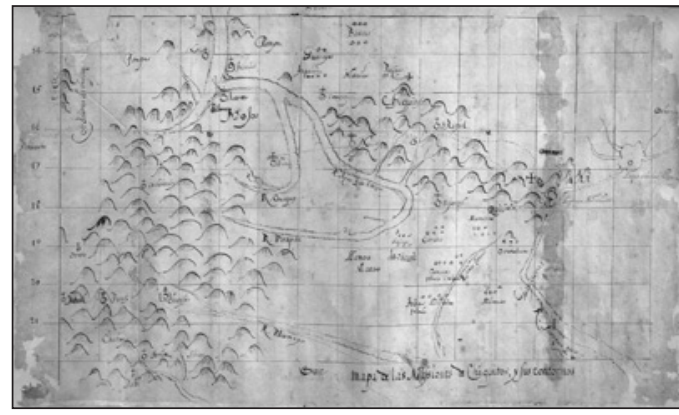

Mapa de las misiones de Chiquitos y sus contornos

3

"Alguno de los compañeros de Hernando de Rivera es el inventor del famoso Paitití, por otro nombre imperio del Gran Mojo. Es el Paitití un riquísimo imperio situado más allá de los Xarayes, en la derecera del Dorado, origen, como algunos falsamente creen, del río Paraguay. Está dicho imperio aislado en medio de una gran laguna, cuya circunferencia ciñen montañas de inestimable riqueza. Los edificios son todos de piedra blanca, con división de calles, plazas y adoratorios. Del centro de la laguna se levanta el palacio del Emperador Mojo, superior a los demás en grandeza, hermosura y riqueza. Las puertas del palacio defienden leones aherrojados en cadenas de oro; los aparadores y vajillas también de oro sirven a la grandeza y ostentación del monarca» (Guevara, 1836, p. 107).

Francisco Menéndez frente a Alejo Carpentier, o sobre la vigencia de los mitos de la conquista

TEODOSIO FERNÁNDEZ ciudad de los Césares en un documento también valorado por el Fiscal de Chile, recogiese velas al final de una carta suya al padre Alzola: «Con todo esto yo no lo creo, y solo envié dicho papel, como antes dije a Vuestra Señoría Reverendísima, para que se entretuviese en el viaje, para lo cual cualquier patraña sirve; pero esta no deja de tener su apariencia de verdad» (Ángelis, 1836f, p. 21).

Resulta evidente, por tanto, que las noticias y rumores sobre la ciudad de los Césares y otras fantasías derivadas de la conquista seguían en circulación durante el siglo XVIII, pero puede advertirse también que la fe en ellas había entrado en crisis. No deja de resultar significativo que el crédulo fiscal Pérez de Uriondo tuviera buen cuidado de que las poblaciones españolas buscadas en territorios australes no se asociaran con El Dorado, el Gran Paytiti o la Gran Quivira, esos lugares imaginados en los móviles y misteriosos límites de la Guayana, del Perú y de la Nueva España, y que, por si el testimonio de Silvestre Antonio de Rojas se revelara falso, argumentase que era la ocasión al menos para salir de dudas y aun para «descubrir con una buena chalupa, las ensenadas y puertos que hay desde el Cabo de San Antonio al Estrecho de Magallanes, y si los dos grandes ríos de las Barrancas y Tunuyan son navegables tierra adentro» (Ángelis, 1836c, p. 10), invocando la importancia que tales descubrimientos pudiera tener para los intereses del rey y para la seguridad del puerto de San Julián y de otros que se descubriesen frente a las amenazas de países rivales. La colección de Pedro de Ángelis permite comprobar que, aunque no sin vacilaciones, una actitud crítica se fue abriendo paso a lo largo del siglo, y que tal actitud estuvo muy ligada a las exploraciones realizadas entonces para un conocimiento más preciso de la geografía americana. Por lo que se refiere al territorio argentino, la primera muestra fue tal vez el Diario de un viaje a la costa de la mar magallánica en 1745, desde Buenos Aires hasta el Estrecho de Magallanes; formado sobre las observaciones de los PP. Cardiel y Quiroga, por el P. Pedro Lozano, texto que cabe interpretar como una consecuencia inicial de los esfuerzos que Es- paña desarrolló a partir de 1740 para asentarse en esa costa patagónica, real o aparentemente codiciada por Inglaterra y por otras potencias europeas. El desaliento ante la dificultades para poblar en la desértica bahía de San Julián que reflejaba ese diario -«todo lo que decían de esos ríos los extranjeros es una mera y pura patraña, pues tal río no se halla, ni señas de haberle jamás habido; que al fin es verdadero el adagio castellano, que, a luengas tierras, luengas mentiras» (Ángelis, 1836h, pp. 2122) - se proyectaba ya decididamente sobre las leyendas en circulación.

De la actitud que se iba imponiendo es buen ejemplo el padre José Guevara, quien, al ser expulsada la Compañía de Jesús de los territorios hispánicos en 1767, dejó manuscrita la Historia del Paraguay, Río de la Plata y Tucumán que Pedro de Ángelis incluyó en el tomo segundo de su colección. Guevara aceptaba que alguna vez hubieran existido gigantes, a juzgar por «antiguos vestigios, que de tiempo en tiempo se descubren sobre el Carcarañal y otras partes», pero consideraba «inverosímil la existencia de los enanos, que se fingen escondidos en cuevas subterráneas para que no los hallemos, y solo se les permite salir en la obscuridad de la noche para que no los veamos» (Guevara, 1836, pp. 7-8). $\mathrm{La}$ existencia de pruebas dignas de tenerse en cuenta justificaba su actitud en el primer caso, mientras en el segundo reiteraba el escepticismo con el que solía abordar las leyendas de la conquista, como al recordar la poderosa flota que en septiembre de 1534, al mando de Pedro de Mendoza, salió desde Sanlúcar «a la conquista del Rey blanco o plateado, que ideó la fantasía de Gaboto o sus agentes, para adquirir nombre de grandes con la novedad del hallazgo» (p. 88). No fue menos contundente con las fábulas «del famoso Paitití, por otro nombre imperio del Gran Mojo» ${ }^{3}$, antes de concluir que «estas y semejantes invenciones publicaron los antiguos y renuevan los novelistas del Gran Mojo, aquellos sobre la $\mathrm{fe}$ de un testimonio primeramente escondido y después honrado con la luz pública, y estos sobre el dicho de los antiguos. Pero leídos los que tocan ese punto, y enterado de la geografía del terreno, se ve que el Paitití es un reino fabuloso, que no tiene cabida en toda la América, y que sus inventores no merecen elogio más honrado que el de soñadores» (p. 108). La expedición que Gonzalo Abreu proyectó realizar a Trapalanda a finales de 1578 daba 
ocasión a Guevara para recordar «la ciudad o ciudades de Césares, por otro nombre $\mathrm{Pa}$ tagones», cuya existencia parecía confirmada en los últimos años del siglo anterior «con la narración de uno que dijo haber estado en la ciudad de los Césares, hablado y comunicado con ellos»-aunque «Nos Dios tener, Papa querer, Rey saber» fue lo único que entendió (p. 149)-, y para, tras examinar declaraciones y pruebas, concluir que «Césares tan circunstanciados son entes imaginarios, que hizo existentes el vulgo con ficciones y novelas» (p. 152).

Precisamente la «experiencia» de quienes habían estado en la ciudad de los Césares fue lo que animó a mantener las dudas sobre su existencia. Esas dudas afectaban a Lozano, que si consideraba «un puro embeleco inventado para el divertimento cuanto se dice del Paytiti», no se atrevía a hacer lo mismo con esa misteriosa ciudad ${ }^{4}$, de la que también había dado fe un sujeto "caballero del orden de Santiago y corregidor que fue de Lipes», quien habría propuesto su conquista al rey Carlos II tras haber estado allí junto con holandeses que se habían entendido con sus habitantes mientras él no había conseguido comprender «sino estas palabras: Nos Dios tener: Papa querer, rey saber», también citadas por Guevara. "Yo ni la niego, ni la creo, cierto de que todo puede ser que haya tal ciudad, y que esté aún oculta, y también que esta fama sea como otras que han salido en estas partes, tan inciertas, permitiendo Dios estos engaños para que así se propague la ley evangélica, o por otros altos fines de su providencia inescrutable» (1873, pp. 169-170), se limitaba a concluir Lozano. Cabe deducir, pues, que el escepticismo iba imponiéndose progresivamente, y que fueron varios los afectados, como puede comprobarse al comparar el «Derrotero desde la ciudad de Buenos Aires hasta la de los Césares, que por otro nombre llaman la Ciudad Encantada, por el P. Tomás Falkner, jesuita (1760)» (Ángelis, 1836g) con A Description of Patagonia and the adjoining parts of South America, la obra que Falkner publicó en Londres en 1774 y cuya traducción castellana editó Pedro de Ángelis. Si antes ampliaba y enriquecía el testimonio de Silvestre Antonio de Rojas, ahora Falkner había perdido por completo la fe en la ciudad de los Césares, cuya noticia entendía "causada de no entender la razón que dan los indios», quienes se referían a
Buenos Aires cuando en Chile daban noticia de una colonia española remota, y a Chiloé o Valdivia cuando lo hacían al este de la cordillera. Por lo demás, consideraba imposible que doscientos o trescientos europeos hubieran permanecidos aislados durante doscientos años «sin haber sido extirpados, muertos, o hecho esclavos por los indios, o sin perder las apariencias de europeos, entremezclándose con ellos» (Falkner, 1835, pp. 45-46), y más en tierras tan inhóspitas, aunque no por eso libres de gentes de paso que jamás habían topado con ciudad alguna.

Indudablemente, las fantasías eran desplazadas sin piedad por las exploraciones que, con una precisión creciente, trataban de fijar la geografía americana, tarea a la contribuyeron varios de los jesuitas nombrados. Fue el caso de José Quiroga, que había realizado para el Gobierno de Buenos Aires la medición de las tierras del ejido de la ciudad, y después elaboró el mapa del territorio de Misiones y del curso del río Paraguay, trabajo relevante para la fijación de los límites entre los dominios de España y Portugal que se pactaron en Madrid el 13 de enero de 1750. Tales empresas se hicieron más exigentes a medida que avanzaba el siglo, y baste recordar entre ellas las de Félix de Azara, de quien Pedro de Ángelis publicó el Diario de la navegación del río Tebicuarí que daba cuenta de la exploración realizada en agosto y septiembre de 1785, y que es otra muestra de los minuciosos reconocimientos del terreno que le eran característicos. A la hora de comprobar la precisión geográfica de las exploraciones realizadas por entonces y valorar la vigencia de la leyenda de la Ciudad de los Césares a finales del XVIII, ningún testimonio ofrece tanto interés como los diarios en los que fray Francisco Ménendez dejó constancia de los viajes realizados desde que, luego de llegar a Lima el 4 de junio de 1790, el virrey Francisco Gil y Lemus le ordenara regresar a Chiloé «con el único fin de descubrir la Laguna de Nahuelhuapi, y registrarla cinco leguas en contorno» (Menéndez, 1900 , p. 164). Esa misión lo llevó a abandonar Castro el 3 de enero de 1791 para regresar a San Carlos (hoy Ancud), por entonces capital del archipiélago, el 14 de marzo, sin haber conseguido el objetivo ni haber mencionado ciudad alguna. Pero el 21 de noviembre de ese año iniciaba desde Castro un nuevo intento y también un nuevo diario, pródigo ahora en la enumeración de lugares transitados y

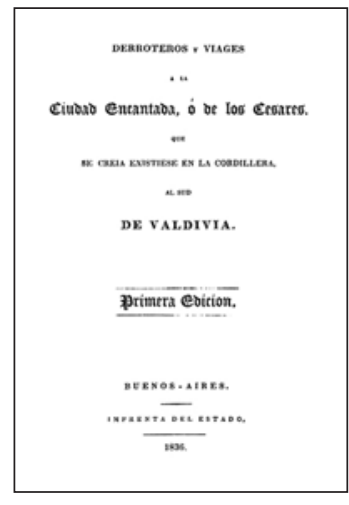

4

No en vano incluía en el tomo cuarto de su Historia del Paraguay, Río de la Plata y Tucumán (1873, pp. 327-332) la relación del marinero Pedro de Oviedo y del marinero y carpintero de ribera Antonio de Coba, miembros de la expedición organizada en 1539 por Gutierre de Vargas Carvajal, obispo de Plasencia, y dirigida por fray Francisco de Ribera, quien viajaba en la nave que se creyó perdida en el estrecho de Magallanes. Sus supervivientes serían precisamente los «césares»- «por haber sucedido su desgracia en el reinado del invictísimo césar Carlos Quinto» (p. 335)-, que al mando de Santiago de Argüello se habrían dirigido hacia el noroeste y habrían fundado una ciudad próxima a los dominios de un enigmático Topa Inga, desde la que esos dos fugitivos habían conseguido llegar a Concepción en 1567, difundiendo las noticias que estimularon la expedición que Gonzalo Abreu pretendió organizar en Tucumán algunos años después.

Francisco Menéndez frente a Alejo Carpentier, o sobre la vigencia de los mitos de la conquista

TEODOSIO FERNÁNDEZ 


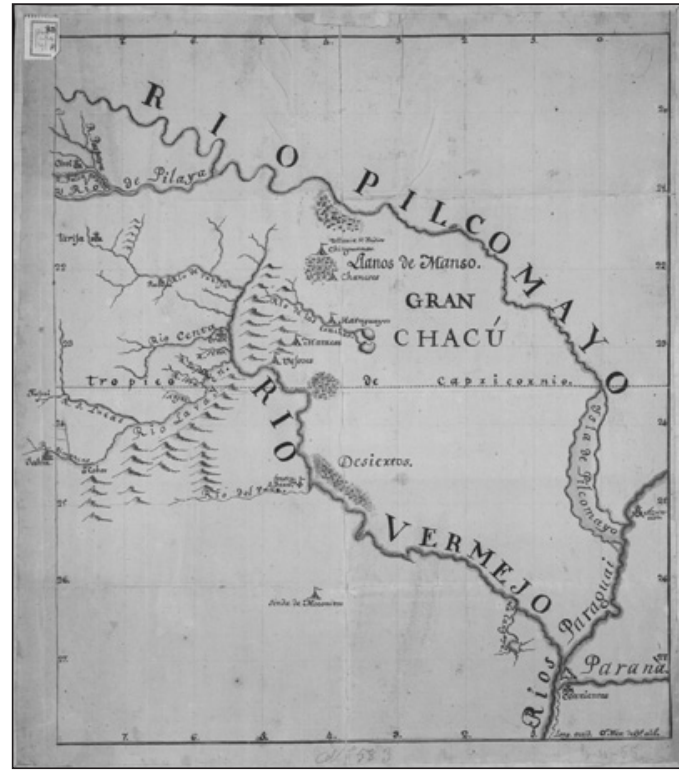

de dificultades superadas frente a una naturaleza sumamente hostil hasta conseguir repasar la cordillera y llegar a la laguna, el 12 de enero del año siguiente. Menéndez no encontró españoles, aunque algunos procedentes de Buenos Aires habían justificado recientemente su mala fama y los recelos de los primeros indígenas que halló la expedición, indios puelches cuyos temores estarían justificados sobre todo por la proximidad de «aucahuincas» o españoles rebeldes, que no tardaron en ser identificados como "aucapicunches» (1900, pp. 304 y 309) o indios rebeldes del norte. En algún momento pareció atisbarse el rastro de la leyenda, a la vista de los caballos de los indios del cacique Mancúuvunay, que los tenían «muy especiales, y algunos con marca», lo que suscitó las sospechas del fraile: «Presumo que los robaron a unos españoles que dicen hay al sur, de donde acaban de venir, y dicen que han tardado tres meses en el viaje: que andan bien vestidos y que no tienen armas, de que presumo que la relación de Rojas no va muy fuera de camino» (1900, p. 309), anotaba el 23 de enero, en su primera alusión al asunto. La última llevaría fecha del 26 del mismo mes: «Propuse a los caciques el ir a ver a los españoles que hay al norte y al sur, y dijeron que volviese temprano el año que viene, que se pondría en ejecución nuestro deseo, y que fiásemos en ellos. Me parece que cumplirán su palabra según las demostraciones que hicieron» (1900, pp. 314-315).

Poco interesado en la fantasmagórica ciudad, Menéndez emprendió el regreso de inmediato, para llegar a San Carlos el 6 de febrero y a Lima el 31 de marzo, con objeto de informar al virrey. Este, a pesar de las protestas que los pehuenches elevaron a los gobernadores de Valdivia y Chiloé por la irrupción, encargó al fraile explorador una tercera entrada, con objeto de «continuar sobre el descubrimiento de la nación de los aucahuincas que habitan a las orillas del río Limec, y los que según las noticias que en el año anterior le dio el cacique Masquionai se hallan a la parte del sur» (Menéndez, 1900, p. 349). Las ilusiones parecían más alentadas por el virrey que por Menéndez, a quien se exigía «un diario exacto y circunstanciado, con distancias, rumbos, señales y cuanto estime conducente, formando las demarcaciones, vistas y planos que pueda; relacionando las noticias que den los indios» (Menéndez, 1900, p. 351), como era habitual en las expediciones de la época. Una nueva rebelión de los indígenas de Osorno retrasó la salida del puerto de San Carlos de Chiloé hasta el 9 de enero de 1793, llegando los expedicionarios a Nahuel Huapi el 18 de febrero. Esta vez Mancúuvunay, requerido sobre su promesa de guiar a Menéndez hasta los huillihuincas (españoles del sur) y aucahuincas, «dijo que él no había dicho tal cosa» y además afirmó «que no los había en el norte, y los del sur estaban a cinco meses de camino» (Menéndez, 1900, p. 363). El periplo por el río Limay concluyó el día 11 de marzo, cuando, en las proximidades de la confluencia con el río Collón Curá, Menéndez tomó el camino de regreso sin haberse adentrado en los territorios de un brumoso cacique Coluna o Colunahuel que parecía tener a unos aucahuincas «acosados en el monte» (Menéndez, 1900, p. 367). Quizá se sintió desorientado ante las informaciones de una india que decía haber estado en un lugar que denominaba "Chiquito Buenosayres» y que él no conseguía identificar ni con Buenos Aires ni con Mendoza (Menéndez, 1900, pp. 367-368). Antes de llegar a Nahuel Huapi ya había podido escuchar testimonios de otros dos indígenas a propósito de ese Chico Buenosayres en el que había sacerdotes como él, sin sospechar que se trataba del Fuerte del Carmen, la población fundada a principios de 1879 cerca de la desembocadura del río Negro.

El día 4 de abril de 1893 Menéndez estaba de regreso en San Carlos. Los resultados de la expedición habían sido positivos: las riberas de la laguna Nahuel Huapi ofrecían todo lo necesario para que prosperara la misión que los franciscanos deberían fundar allí en beneficio de los indígenas de la zona y como base para el descubrimiento de las naciones del sur. La Ciudad de los Césares iba quedando en el olvido para él, aunque no para el virrey Gil y Lemus, quien, deseoso de resolver el asunto de los aucahuincas, hizo que el fraile preparara una cuarta expedición, la última. Menéndez volvió a salir de San Carlos el 8 
de enero de 1794, y el 11 de marzo estaba ya de regreso. En las proximidades de la laguna Nahuel Huapi se encontró esta vez con otra india y con el hermano de Mancúuvunay, quienes decían haber tratado con huillihuincas: probablemente se trataba de recuerdos y de vagas noticias, unos y otras relacionados con la Guardia de San José, fortín y puerto instalados a principios de 1779 en la península de ese nombre (hoy Valdés), y con el establecimiento de San Julián, fundado en 1780 como «colonia Floridablanca», que habían ido desapareciendo desde que una cédula real de 1 de agosto de 1783 ordenara abandonar los establecimientos patagónicos con excepción de los instalados a orillas del Río Negro ${ }^{5}$. Pero pronto la seguridad de los expedicionarios se vio amenazada por la llegada de grupos indígenas del sur y del este, al parecer tehuelches o «patagones» en su mayoría, cuya actitud hostil determinó que Menéndez decidiera el regreso a Chiloé.

La lectura de sus diarios permite deducir que si Menéndez no identificó a los huillihuincas con los asentamientos españoles del Atlántico fue por no defraudar al virrey ni -como se desprende de una «respuesta» fechada en San Carlos el 18 de marzo de 1794- a Pedro de Cañaveral, gobernador y comandante general de Chiloé. Pero la Ciudad de los Césares no volvió a justificar expedición alguna, confirmando que el siglo XVIII se caracterizó no tanto por haber mantenido vigente una geografía imaginaria como por haberla reemplazado por otra real, consecuencia del nuevo espíritu con que se exploraron aquellas tierras, sobre todo en la segunda mitad de la centuria. La desaparición de los mitos y leyendas fue menos un resultado de su cuestionamiento expreso que de su progresiva ausencia en los informes y diarios de viaje, tan abundantes en la época como unánimes en mostrar el descrédito creciente de los mitos de la conquista, contra los que se conjuraban tanto el fracaso de las expediciones que trataron de confirmar esas fantasías como el avance de un empirismo racionalista acorde con el espíritu de la Ilustración, impulsor de las exploraciones y determinante de los escritos que daban cuenta de ellas.

Naturalmente, para Alejo Carpentier el nacimiento y la vigencia de una realidad legendaria era más atractivos que su extinción, y prefirió ignorar ese proceso, como ignoró que el culto de la Razón y la fe en el Ser Su- premo quizá no fueran las mejores muestras de ese racionalismo europeo que él trataba de contraponer a la imaginación americana. Por lo demás, la capacidad para propalar fantasías no era exclusivamente hispánica: el relato de la vuelta al mundo que el comodoro John Byron dio en el Dolphin, en 1764, confirmaba que la estatura de los patagones «era tan extraordinaria que aun sentados así, venían a ser tan altos como el comandante en pie» (Byron, 1769 , p. 67), cuando ya se habían reiterado los testimonios hispánicos que cuestionaban la existencia de tales gigantes. $\mathrm{Ni}$ siquiera fue española una concreción literaria que la leyenda de la Ciudad de los Césares produjo en el siglo XVIII: en An account of the First Settlement, Laws, Form of Governement, and Police of the Cessares: A People of South America, in nine Letters (1764), obra de contenido claramente utópico, el inglés James Burgh la imaginó poblada por holandeses, según la leyenda que también había encontrado acogida en José Cardiel6. La fuente común, reconocida por Cardiel, estaba probablemente en la Histórica relación del Reino de Chile del jesuita Alonso de Ovalle, quien se había referido a la jornada a los Césares que entre noviembre de 1620 y agosto de 1621 dirigiera Jerónimo Luis de Cabrera, gobernador de Tucumán, y a noticias proporcionadas desde Chiloé por el padre Jerónimo de Montenegro acerca de "gente muy blanca y rubia, bien dispuesta y agestada», que bien podrían ser los españoles supervivientes de la armada que naufragó en el estrecho de Magallanes, «si no es que ya vengan de alguna otra de holandeses que hayan padecido por aquel paraje la misma fortuna» (Ovalle, 1646, p. 72), como cabía deducir tanto del color de la piel y del pelo como de que hablaran una lengua que no habían conseguido entender quienes daban noticia de ellos.

Naturalmente, nada de esto interesó a Carpentier, hijo de su tiempo y de una herencia ya rica en esa visión de los conquistadores que en el prólogo a El reino de este mundo lo animaba a recordar que solamente los quijotes eran capaces de introducirse plenamente en el mundo caballeresco de Amadis de Gaula o Tirante el Blanco, aquellas novelas capaces de sobrevivir al escrutinio realizado por el cura y el barbero en la biblioteca de Alonso Quijano. No es difícil comprobar que aprovechaba una propuesta que se había afianzado en la cultura hispanoamericana al menos desde que en «La filosofía del Quijote

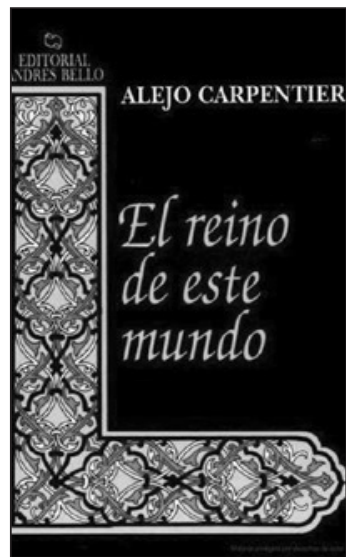

5

Véase el «Informe del Virrey Vértiz, para que se abandonen los establecimientos de la costa patagónica», fechado el 22 de febrero de 1783, donde se puso fin a las ilusiones depositadas en aquellos territorios y al temor de que atrajeran el interés de otros países, lo que parecía difícil, "por la calidad de sus terrenos, por falta de buenos puertos, por las excesivas mareas, por lo rigoroso del clima y otras causas» (Ángelis, 1837, p. 122).

6

En su carta al Gobernador y Capitán General de la Provincia de Buenos Aires, ya mencionada, Cardiel hizo referencia a «un corregidor del Perú, llamado Quirós ○ Quiroga»-quizá derivado del Benito Quiroga imaginado por Feijoo y por Lozano a partir de Cortés Osorio- como autor de una relación en la que narraba su viaje desde Amberes hasta una extraña ciudad próxima al estrecho de Magallanes cuyos habitantes hablaban una lengua de la que «nombrar Rey y Papa» fue lo único que alcanzó a comprender», y también se hizo eco del relato de una cautiva que, habiendo huido de sus captores indígenas, "encontró unas casas, y en ellas gente blanca y rubia; y que estando ella muy alegre, juzgando ser gente española, se le ahogó todo el contento, viendo que no les entendía palabra», de lo que dedujo que podía tratarse "de gente holandesa, o inglesa; que también dicen que se han perdido en el estrecho navíos holandeses» (Ángelis, 1836e, pp. 15-16).

Francisco Menéndez frente a Alejo Carpentier, o sobre la vigencia de los mitos de la conquista

TEODOSIO FERNÁNDEZ 
y el descubrimiento de América», ensayo que escribió en 1916 cuando se acercaba la conmemoración del tercer centenario de la muerte de Cervantes, José Enrique Rodó identificó una filosofía común en la conquista del nuevo mundo y en la gran novela cervantina, lo que lo animaba a recordar que América fue «el escenario de proezas más inauditas y asombrosas que las aventuras baldías de los caballeros andantes» (1918, p. 30). Cabe pensar que hasta entonces la valoración del Quijote en relación con los excesos de la fantasía había sido exactamente la contraria: a propósito de la leyenda de las amazonas ya había observado Pedro de Ángelis, en nota incluida en el índice geográfico e histórico añadido a la Historia argentina del descubrimiento, población y conquista de las provincias del Río de la Plata, de Ruy Díaz de Guzmán, que, «cuando se lee la historia de los viajes y descubrimientos que iniciaron los europeos al salir de la XV centuria, no debe olvidarse que era la época de las ideas romanescas, y que aún no habían sido ridiculizadas por el genio inimitable de Cervantes» (Díaz de Guzmán, 1835, p. IV). Inicialmente Rodó también parecía decidido a dar la razón a Cervantes y a condenar la imaginación alocada característica de aquellas novelas, pero al final prefirió seguir el ejemplo de Alonso Quijano y declarar su fe en una realidad y una historia capaces de superar las fantasías más inverosímiles. Al relacionar la irrupción española en América con las hazañas narradas en los libros de caballerías y con el Quijote, ofreció ya esa visión de la empresa española que permitiría a Carpentier asegurar que la Historia verdadera de la conquista de la Nueva España de Bernal Díaz del Castillo es «el único libro de caballería real y fidedigno que se haya escrito -libro de caballería donde los hacedores de maleficios fueron teules visibles y palpables, auténticos los animales desconocidos, contempladas las ciudades ignotas, vistos los dragones en sus ríos y las montañas insólitas en sus nieves y humos» (1966, p. 93).

Desde luego, Rodó no fue el único responsable del interés que los mitos de la conquista suscitaron entre los escritores hispanoamericanos. Sin el tratamiento hiperbólico que lo real maravilloso americano habría de exigir, las extraordinarias hazañas de los conquistadores ya habían quedado estrechamente ligadas a esos mitos apenas iniciado el siglo XX, como permite comprobar Blasón de plata, el ensayo que para exaltación de la República Argentina en el centenario de su independencia escribió Ricardo Rojas en 1910, aunque no se publicara hasta 1912: allí puede encontrarse una documentada información sobre las leyendas relacionadas con el valle de Jauja, la ciudad de los Césares y el imperio de las amazonas, leyendas que Rojas ligaba al nacimiento de la nación argentina. Aunque también subrayaba la capacidad de la tierra americana para dar un alma común a sus habitantes, Blasón de plata fue ante todo el primer libro significativo sobre los mitos de la conquista, que durante toda la primera mitad del siglo pasado habrían de merecer una atención creciente, justificada por esa identificación del carácter de los conquistadores con el espíritu quijotesco que desde 1898, en oposición al materialismo anglosajón triunfante, se había convertido en atributo definitorio del idealismo hispánico. Tales planteamientos eran los que recibía y reelaboraba Carpentier mientras escribía La música en Cuba, si no antes. En busca de datos para ese libro, leyó a los cronistas de Indias con atención, lo que le permitió comprobar que, mientras en la isla esperaban la oportunidad de saltar al continente, «los Hernán Cortés, Pedro de Alvarado, Diego Ordaz, Bernal Díaz del Castillo, soñaban ya, aunque sin haber adivinado sus nombres, con los futuros grandes mitos de América: el El Dorado, el Potosí, el tesoro de los Incas, la fuente de la eterna juventud. Preparaban su entrada en la mitología nueva, que ellos mismos crearían con su arrojo» (1946, p. 20). No le fue difícil concluir que la imaginación había impulsado las exploraciones tanto o más que las riquezas comprobadas del Incario y del cerro de plata de Potosí: en efecto, la búsqueda de la Fuente de la Eterna Juventud determinó los intentos de conquistar la Florida; el mito de El Dorado alentó las expediciones de Gonzalo Jiménez de Quesada, Sebastián de Belalcázar y Nicolás de Federman que confluyeron en la altiplanicie donde el primero de ellos fundó Santa Fe de Bogotá en 1538, y otras no menos arriesgadas después, como la que en 1541 inició Gonzalo Pizarro en busca del país de la Canela y que llevó a Francisco de Orellana a recorrer por primera vez el Río Grande las Amazonas hasta su desembocadura, o las que se adentraron en las selvas del Orinoco con Antonio de Berrío, quien intentó llegar a la imaginaria laguna y ciudad de Manoa en 1584 y 1591. 
A esos mitos de la conquista convenía la geografía americana del río Caroní y de la Gran Sabana, el reino de las rocas y de las aguas al que Carpentier dio una significación acorde con sus planteamientos culturales de su tiempo al afirmar que ese mundo del Génesis «halla mejor su expresión en el lenguaje americano del Popol Vub que en los versículos hebraicos de la Biblia» (1985a, p. 172). Menos que por su relación con aquella España lejana que, deslumbrada por las noticias y las riquezas que llegaban de ultramar, «se iba habituando a admitir que, en América, lo fantástico se hacía realidad» (1985a, p. 180), en los años cuarenta del siglo pasado los mitos de la conquista interesaron por lo mucho que parecían revelar sobre la realidad americana y su capacidad para alimentar y conservar mitos como los creados por «esos otros poetas que fueron los aventureros capaces de jugarse la vida sobre la fe de una leyenda» (1985a, p. 182), mitos que, al analizar la historia del nuevo mundo, se configuraban como elementos definitorios de una identidad diferente, como manifestaciones propias de una cultura que se resistía al racionalismo de la civilización europea.

No conviene ignorar la raíz romántica de esos planteamientos, que el propio Carpentier permite comprobar: el estreno de la ópera Tristán e Isolda en Caracas, en octubre de 1948, le dio ocasión para señalar la «evidencia desafiante» que la obra de Richard Wagner representaba frente a las discusiones inútiles «en torno al "formalismo", al "arte enrolado”, al arte para las masas» (1949b, p. 27), y a la vez para vindicar el romanticismo que las vanguardias habían menospreciado. Carpentier sentía que el romanticismo seguía vivo al observar las pretensiones de hacer un arte propio que llevaban a los escritores y artistas latinoamericanos al encuentro con su tierra, en una reacción que reconocía nacionalista por los principios que la impulsaban. Románticos eran en su opinión tanto la historia de América como los sentimientos y la expresión peculiar del hombre americano, e incluso la tarea adánica del escritor que aún tenía ante sí la misión de descubrir el paisaje del nuevo mundo y de dar nombre a sus animales y a sus plantas. Para tal tarea bien podía servir de referencia ese Wagner que halló lo universal en las entrañas de lo local, en la imaginación alemana, en los mitos germánicos y escandinavos. Si Carpentier reclamaba atención para el nuevo mundo mientras se ocupaba de Tristán e Isolda, lo hacía porque estaba convencido de que América tenía mucho y muy interesante que revelar a quien estuviese dispuesto a creer en ella, a describir su geografía y a trabajar para que su historia y sus mitos encontraran un lugar en el ámbito universal de la cultura. Esos planteamientos no eran los de los escritores hispanoamericanos del siglo XVIII, ni siquiera cuando se ocuparon de la ciudad de los Césares: interesados en explorar su entorno geográfico y humano, nada podía resultar más ajeno a su afán de conocimiento que la voluntad de adaptar ese entorno a convicciones previas, como la fe en lo real maravilloso americano pareció exigir.

\section{Bibliografía}

Ángelis, Pedro de (1836a), «Discurso preliminar a las noticias y derroteros de la ciudad de los Césares», en Derroteros y viajes a las Ciudad Encantada, o de los Césares, que se creía existiese en la cordillera, al sud de Valdivia, Buenos Aires, Imprenta del Estado. Colección de obras y documentos relativos a la historia antigua y moderna de las provincias del Río de la Plata, tomo primero.

Ángelis, Pedro de (1836b), «Declaración del capitán D. Fermín Villagrán, sobre la ciudad de los Césares (1871)», en Derroteros y viajes a la Ciudad Encantada, o de los Césares, que se creía existiese en la cordillera, al sud de Valdivia, pp. 42-43.

Ángelis, Pedro de (1836c), «Derrotero de un viaje desde Buenos Aires a los Césares, por el Tandil y el Volcán, rumbo al sudoeste, comunicado a la corte de Madrid, en 1707, por Silvestre Antonio de Roxas, que vivió muchos años entre los indios peguenches», en Derroteros y viajes a la Ciudad Encantada, o de los Césares, que se creía existiese en la cordillera, al sud de Valdivia, pp. 3-10.

Ángelis, Pedro de (1836d), «Relación de las noticias adquiridas sobre una ciudad grande de españoles, al sud de Valdivia, e incógnita hasta el presente, por el capitán D. Ignacio Pinuer (1774)», en Derroteros y viajes a la Cindad Encantada, o de los Césares, que se creía existiese en la cordillera, al sud de Valdivia, pp. 27-37.

Ángelis, Pedro de (1836e), «Carta del padre jesuita José Cardiel, escrita al señor
Francisco Menéndez frente a Alejo Carpentier, o sobre la vigencia de los mitos de la conquista

TEODOSIO FERNÁNDEZ 
Gobernador y Capitán General de la Provincia de Buenos Aires, sobre los descubrimientos de las tierras patagónicas, en lo que toca a los Césares (11 de agosto de 1746)», en Derroteros y viajes a la Ciudad Encantada, o de los Césares, que se creía existiese en la cordillera, al sud de Valdivia, pp. 11-15.

Ángelis, Pedro de (1836f), «Capítulo de una carta del P. Lozano al P. Juan de Alzola, sobre los Césares, que dicen están poblados en el estrecho de Magallanes», en Derroteros y viajes a la Ciudad Encantada, o de los Césares, que se creía existiese en la cordillera, al sud de Valdivia, pp. 19-21.

Ángelis, Pedro de (1836g), «Derrotero desde la ciudad de Buenos Aires hasta la de los Césares, que por otro nombre llaman la Ciudad Encantada, por el P. Tomás Falkner, jesuita (1760)», Buenos Aires, Imprenta del Estado, 1836, en Derroteros y viajes a la Ciudad Encantada, o de los Césares, que se creía existiese en la cordillera, al sud de Valdivia, pp. 22-26.

Ángelis, Pedro de (1836h), Diario de un viaje a la costa de la mar magallánica en 1745, desde Buenos Aires hasta el Estrecho de Magallanes; formado sobre las observaciones de los PP. Cardiel y Quiroga, por el P. Pedro Lozano, Buenos Aires, Imprenta del Estado. En Pedro de Ángelis, Colección de obras y documentos relativos a la bistoria antigua y moderna de las provincias del Río de la Plata, tomo primero.

Ángelis, Pedro de (1837), «Informe del Virrey Vértiz, para que se abandonen los establecimientos de la costa patagónica», en Colección de viajes y expediciones a los campos de Buenos Aires y a las costas de la Patagonia, Buenos Aires, Imprenta del Estado, pp. 122-127. En Pedro de Ángelis, Colección de obras y documentos relativos a la historia antigua y moderna de las provincias del Río de la Plata, tomo quinto.

Byron, John (1769), Viaje del comandante Byron alrededor del mundo, becho últimamente de orden del almirantazgo de Inglaterra, traducido del inglés por el Dr. D. Casimiro de Ortega, Madrid, en Casa de D. Francisco Mariano Nipho.

Carpentier, Alejo (1946), La música en Cuba, México, Fondo de Cultura Económica.

Francisco Menéndez frente a Alejo los mitos de la conquista

TEODOSIO FERNÁNDEZ ición y Distribución Ibero Americana de Publicaciones S. A.).

Carpentier, Alejo (1949b), «Tristán e Isolda en Tierra Firme (reflexiones al margen de una representación wagneriana)», en $\mathrm{Cul}$ tura Universitaria, Dirección de Cultura de la Universidad Central de Venezuela, número 13, Caracas, mayo-junio de 1949, pp. 23-61.

Carpentier, Alejo (1966), «De lo real maravilloso americano», en Alejo Carpentier, Tientos y diferencias, La Habana, Ediciones Unión, pp. 84-99.

Carpentier, Alejo (1985a), «Visión de América. La Gran Sabana: mundo del Génesis», en Alejo Carpentier, Obras completas, vol. VIII, Crónicas 1. Arte, literatura, politica, México, Siglo XXI Editores, pp. 169-174.

Carpentier, Alejo (1985b), «Visión de América. El Salto del Ángel en el reino de las aguas», en Alejo Carpentier, Obras completas, vol. VIII, Crónicas 1. Arte, literatura, política, México, Siglo XXI Editores, pp. $175-182$.

Cortés Osorio, Juan (1677), Reparos historiales apologéticos [...], propuestos de parte de los misioneros apostólicos del imperio de la China, representando los descuidos que se cometen en un libro que se ba publicado en Madrid, en grave perjuicio de aquella misión, Pamplona, por Tomás Baztán.

Díaz de Guzmán, Ruy (1835), Historia argentina del descubrimiento, población y conquista de las provincias del Río de la Plata escrita por Ruy Díaz de Guzmán en el año 1612, Buenos Aires, Imprenta del Estado. En Pedro de Ángelis, Colección de obras y documentos relativos a la bistoria antigua y moderna de las provincias del Río de la Plata, tomo primero.

Falkner, Tomás (1835), Descripción de Patagonia y de las partes adyacentes de la América Meridional; que contiene una razón del suelo, producciones, animales, valles, montañas, ríos, lagunas, etc., de aquellos países. La religión, gobierno, política, costumbres y lengua de sus moradores, con algunas particularidades relativas a las islas Malvinas, primera edición castellana, Buenos Aires, Imprenta del Estado, 1835. En Pedro de Ángelis, Colección de obras y documentos relativos a la bistoria antigua y moderna de las provincias del Río de la Plata, tomo primero. 
Feijoo, Benito Jerónimo (1730), «Fábula de las Batuecas, y países imaginarios. Discurso décimo", en Teatro crítico universal, o Discursos varios en todo género de materias, para desengaño de errores comunes, tomo cuarto, Madrid, Imprenta de la Viuda de Francisco del Hierro, pp. 241-267.

Guevara, José (1836), Historia del Paraguay, Río de la Plata y Tucumán, por el P. Guevara, de la Compañía de Jesús, Buenos Aires, Imprenta del Estado, 1836. En Pedro de Ángelis, Colección de obras y documentos relativos a la historia antigua y moderna de las provincias del Río de la Plata, tomo segundo.

Lozano, Pedro (1754), Historia de la Compañia de Jesús en la Provincia del Paraguay, tomo primero, Madrid, Imprenta de la Viuda de Manuel Fernández y del Supremo Consejo de la Inquisición.
Lozano, Pedro (1873), Historia del Paraguay, Río de la Plata y Tucumán, tomo I, Buenos Aires, Casa Editora «Imprenta Popular».

Menéndez, Francisco (1900), Viajes de Fray Francisco Menéndez a Nabuelbuapi, publicados y comentados por Francisco Fonck, Valparaíso, Carlos F. Niemeyer.

Ovalle, Alonso de (1646), Histórica relación del Reyno de Chile, y de las misiones y ministerios que ejercita en él la Compañia de Jesús, Roma, por Francisco Cauallo.

Rodó, José Enrique (1918), «La filosofía del Quijote y el descubrimiento de América», en El camino de Paros (meditaciones y andanzas), Valencia, Editorial Cervantes, pp. 27-31.

Fecha de recepción: 26/06/2013

Fecha de aceptación: 29/07/2013 